Original Research Paper

\title{
Frequency of Single Nucleotide Polymorphisms of the SLCO1B1 Gene in Slavic Population of Central Europe
}

\author{
${ }^{1,2}$ Michaela Mikulová, ${ }^{1}$ Veronika Kramarova and ${ }^{1}$ Ján Chandoga \\ ${ }^{1}$ Institute of Medical Biology, Genetics and Clinical Genetics, \\ Comenius University Faculty of Medicine and University Hospital Bratislava, Slovakia \\ ${ }^{2}$ Department of Genetics, Faculty of Natural Sciences of Comenius University Bratislava, Slovakia
}

Article history

Received: 10-07-2016

Revised: $19-10-2016$

Accepted: 10-12-2016

Corresponding Author: Michaela Mikulová Institute of Medical biology, Genetics and Clinical Genetics Comenius University Faculty of Medicine and University Hospital,

Mickiewiczova 13, 81369

Bratislava, Slovakia

Email: mjurkovicova@gmail.com

\begin{abstract}
The organic anion transporting polypeptide 1B1 (encoded by $S L C O 1 B 1$ gene) is involved in the active cellular influx of diverse endogenous compounds and several drugs, such as HMG-CoA reductase inhibitors (statins). Two common polymorphisms c.388A $>\mathrm{G}$ and c.521T $>\mathrm{C}$ in $S L C O 1 B 1$ alter transport activity of this transporter and play an important role in the pharmaceutical response to many drugs. The aim of our study was to investigate frequencies of common SNPs in SLCO1B1 gene in Western Slavic population. We determined frequencies of two common polymorphisms c.388A $>\mathrm{G}$ and c.521T $>\mathrm{C}$ in the SLCO1B1 gene in the control group consisting of 83 healthy volunteers from Slavic population by PCR-RFLP and allele-specific Real-Time PCR. Presented results were statistically evaluated and compared with known data of different ethnic groups. The allelic frequencies of SLCO1B1 SNPs were $37 \%$ for minor allele c. $388 \mathrm{G}$ and $23 \%$ for c.521C. SLCO1B1 SNPs c. $388 \mathrm{~A}>\mathrm{G}$ and c. $521 \mathrm{~T}>\mathrm{C}$ were relatively frequent in Slovak population and allelic frequencies generally correspond with data published for other population of Caucasian origin. We also determined that $19 \%$ of individuals with Gilbert syndrome (ATA7/7TAA) carried the genotype c.388GG of the $S L C O 1 B 1$ gene. According to our findings, analyzed SNPs in the SLCO1B1 gene are frequent enough for consideration of their screening in patients indicated for treatment with drugs involved in OATP1B1 mediated transport. Detection of polymorphisms in $S L C O 1 B 1$ is beneficial for avoiding adverse drug reaction.
\end{abstract}

Keywords: $S L C O 1 B 1$, Statin, c.521T $>$ C, c.388A $>$ G, Pharmacogenetics

\section{Introduction}

Organic Anion Transporting Polypeptides (OATPs) represent family of proteins, which participate in the membrane transport of endogenous and xenobiotic compounds. OATPs are expressed in many types of tissues, including the liver, lung, heart, kidney, brain, intestine, placenta, testes (Hagenbuch and Meier, 2003).

The organic anion transporting polypeptide 1B1 (encoded by SLCO1B1 gene) is one of the main hepatic uptake transporters, which is localized on the basolateral part of hepatocytes. It is involved in active cellular influx of diverse endogenous substrate, such as bile acids, bilirubin, conjugates of steroid hormone and drugsHMG-CoA reductase inhibitors, fexofenadine, rifampicin, bosentan, valsartan, temocaprilat and irinotecan metabolite SN-38 (Chung et al., 2005; Pasanen et al., 2006a; Cvetkovic et al., 2009; Nishizato et al., 2003; Xiang et al., 2009; Treiber et al., 2007; Maeda et al., 2006). Changes in the activity of this transporter play an important role in pharmaceutical response to many drugs (Niemi et al., 2004).

The SLCO1B1 gene is located on the short arm of a chromosome 12 and spans fifteen exons. It encodes protein of 691 amino acids with 12 transmembrane helices. A lot of allelic variants of SLCO1B1 gene were identified in the past, 190 common variants have minor allele frequency greater than $5 \%$ (http://hapmap.ncbi.nlm.nih.gov/). Interesting for genetic study are c.388A $>$ G (rs2306283) and c. 521T $>C$ (rs4149056) polymorphisms that resulted in the definition of $S L C O 1 B 1 * B$ and $S L C O 1 B 1 * 5$ respectively 
(Nishizato et al., 2003; Tirona et al., 2001). At the variant c.388A $>\mathrm{G}(\mathrm{N} 130 \mathrm{D})$, the wild-type $\mathrm{A}$ allele encodes asparagine while the minor $\mathrm{G}$ allele encodes aspartic acid, at variant c.521T $>\mathrm{C}(\mathrm{V} 174 \mathrm{~A})$, the wildtype $\mathrm{T}$ allele encodes valine while the minor $\mathrm{C}$ allele encodes alanine. These substitutions are associated with altered transport activity of OATP1B1 (Tirona et al., 2001; Nies et al., 2013). Biochemically important feature of these polymorphisms may be impact on elevation of blood bilirubin concentration and SLCO1B1 SNPs could be further possible factor for the induction of hyperbilirubinemia (Huang et al., 2004; 2005). Subsequent unfavorable effect of these polymorphisms is based on their linkage with statininduced myopathy. Association between risk of statininduced myopathy and variant in the SLCO1B1 gene was described by SEARCH study group (GWAS) in 2008 (Link et al., 2008). This association was also identified in next studies (Voora et al., 2009; Brunham et al., 2012; Donnelly et al., 2011; Carr et al., 2013). These findings revealed that SLCO1B1 genotyping can be used to guide choice and/or dose of statin therapy with the goal of reducing the risk of muscle impairment and optimization of adherence to the therapy (Stewart, 2013). Guideline for simvastatin treatment considering SLCO1B1 genotype was suggested by Wilke et al. (2012).

The frequency of c.388A $>\mathrm{G}$ and c.521T $>\mathrm{C}$ varies significantly between different populations worldwide. The c.388A $>$ G SNP allele frequency was observed 30$45 \%$ in Caucasians, $70-80 \%$ in African populations and $60-90 \%$ in Asian populations. The c.521T $>$ C SNP allele frequency was found out to be $10-20 \%$ in European, 10$15 \%$ in Asian populations and $1-4 \%$ in African population (Tirona et al., 2001; Jada et al., 2007; Mwinyi et al., 2008).

Different frequencies in various populations indicate, that pharmacogenetic-testing for these variants is dependent on a particular population genetic architecture. For this purpose, it is important to characterize $S L C O 1 B 1$ genetic variation in different populations. To the best of our knowledge, the study about incidence of SLCO1B1 polymorphisms in Slovak population, has not been published yet. The aim of our study was to analyze SLCO1B1 SNPs gene in Slovak population, to identify frequency and compare our findings with other populations. Whereas polymorphisms in SLCO1B1 gene have impact on bilirubin level, the second aim was to detect incidence of SLCO1B1 SNPs in probands with Gilbert syndrome, characterized by presence of (TA)7 tandem repeat of promoter (TATA box) UGT1A1 gene. In this group we suppose a cumulative genetic effect on hyperbilirubinemia due to influence of both genetic factors on bilirubin metabolism. This study provides valuable information about genetic variability $S L C O 1 B 1$ gene in Western Slavic population.

\section{Materials and Methods}

\section{Sample}

Control group consisted of 83 healthy unrelated subjects 166 alleles from Slovak inhabitants of Slavic origin (48 men and 35 women). All participants signed a written informed consent before entering the study. They were randomly selected from available database of healthy volunteer samples. The data for BMI, clinical and biochemical parameters and the age was also collected, but these data are not relevant for the present study.

\section{Sample Preparation}

Blood samples for DNA extraction were collected in $3 \mathrm{~mL}$ tubes containing potassium EDTA. DNA was isolated from leukocytes using MN NucleoSpin Blood mini (Macherey-Nagel).

\section{Genotyping}

Isolated DNA was screened for two SLCO1B1 polymorphisms c. $388 \mathrm{~A}>\mathrm{G}$ and c.521 $\mathrm{T}>\mathrm{C}$.

Polymorphism c.388A $>\mathrm{G}$ was detected by PCRRFLP using primers published by Mwinyi et al. (2008). The PCR amplification was performed in a PCR thermal cycler and consisted of initial denaturation of 5 minutes at $95^{\circ} \mathrm{C}$ followed by 35 cycles of denaturation for $30 \mathrm{sec}$ at $95^{\circ} \mathrm{C}$, annealing for $30 \mathrm{sec}$ at $51^{\circ} \mathrm{C}$, extension for $30 \mathrm{sec}$ at $72^{\circ} \mathrm{C}$ and a final extension for $10 \mathrm{~min}$ at $72^{\circ} \mathrm{C}$. PCR product was digested with the appropriate restriction enzyme ClaI. Change from $A$ to $G$ creates restriction site for ClaI following $274 \mathrm{bp}$ PCR fragment cleaves to 155 and 119 bp fragment (Mwinyi et al., 2008). RFLP fragment was analyzed on a $2 \%$ agarose gel.

Polymorphism c.521T $>C$ (rs4149056) was analyzed by TaqMan SNP genotyping Assay C_30633906_10 (Applied Biosystems).

Polymorphism in promotor region of UGT1A1ATA7/7TAA was detected by fragment analysis by capillary electrophoresis in genetic analyzer ABI310. Primers

GS1-1: TAACTTGGTGTATCGATTGGTTTTTG and GS1-2: ROX-ACAGCCATGGCGCCTTTGCT were used for amplification of promotor region of UGT1A1 gene.

\section{Statistical Analysis}

The Hardy-Weinberg test was applied to confirm the independent segregation of the alleles of individual genotypes. Fisher's exact test was used for the analysis of differences between populations. Data were analyzed with statistical online software CubeX (Gaunt et al., 
2007) (haplotype analysis, linkage disequilibrium, Hardy-Weinberg test, Chi-square test) and SPSS software (Fisher exact test). The p-value of less than 0.05 was accepted as significant $(\mathrm{p}<0.05)$.

\section{Results}

83 healthy volunteers (166 alleles) from Slovak population were analyzed for 2 polymorphisms in the SLCO1B1 gene and for polymorphism A(TA)6/7TAA in the promotor region the UGT1A1 gene. PCR-RFLP was used to detect polymorphism c.388A $>\mathrm{G}$ (Fig. 1) and allele-specific Real-Time PCR analysis for c.521T $>$ C (Fig. 2a-c) in the SLCO1B1 gene.

The results of our study are shown in Table 1. The frequency of studied polymorphisms is similar to frequency observed in majority of Europe's population. The occurrence of the minor allele $(G)$ of the polymorphism c.388A $>\mathrm{G}$ was $37 \%$ and $13 \%$ of studied subjects carried genotype c.388GG. 521C allele occurrence was $23 \%$ and only $5 \%$ of individuals carried genotype c.521CC. We compared acquired results (Table 1) with allelic frequencies from different ethnic populations (Table 2).

Table 1. Allelic and genotype frequencies of SLCO1BI SNPs in Slovak population

\begin{tabular}{lllll}
\hline SNP & Allele & Frequency $(\%)$ & Genotype & Frequency $(\%)$ \\
\hline c.388A $>$ G & A & 63 & AA & 40 \\
& G & 37 & AG & 47 \\
c.521T $>$ C & & 77 & GG & 13 \\
& T & 23 & TT & 58 \\
& C & & TC & 37 \\
\hline
\end{tabular}

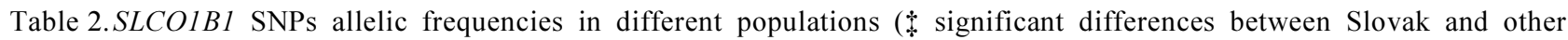
populations, $\mathrm{p}<0.05$

\begin{tabular}{|c|c|c|c|c|c|c|}
\hline Population & Number & c. $388 \mathrm{~A}>\mathrm{G}$ & $\mathrm{p}_{\text {value }}^{\mathrm{a}}$ & c. $521 \mathrm{~T}>\mathrm{C}$ & p value $^{\mathrm{b}}$ & Refs. \\
\hline Slovak & 83 & $37(29.4-44.6)^{*}$ & & $23(17,3-30,7)^{*}$ & & Current study \\
\hline German & 300 & 36,5 & 1.000 & $15 t$ & 0.019 & (Mwinyi et al., 2008) \\
\hline Hungarian & 442 & 36.2 & 0.930 & 18,9 & 0.241 & (Nagy et al., 2015) \\
\hline Roma & 470 & $54,5 \div$ & 0.000 & 17,2 & 0.100 & (Nagy et al., 2015) \\
\hline Turkish & 94 & 46,3 & 0.084 & $12,2 \%$ & 0.011 & (Mwinyi et al., 2008) \\
\hline White Canadian & 41 & 50 & 0.055 & 18,3 & 0.510 & (Boivin et al., 2010) \\
\hline African & 115 & $77,8 \div$ & 0.000 & $3,9 \%$ & 0.000 & (Mwinyi et al., 2008) \\
\hline European American & 49 & 30,6 & 0.349 & 14,3 & 0.109 & (Tirona et al., 2001) \\
\hline African American & 22 & $75,0 \dagger$ & 0.000 & $2,3 \%$ & 0.001 & (Tirona et al., 2001) \\
\hline Japanese & 120 & $62.9 \%$ & 0.000 & 15,8 & 0.092 & (Nishizato et al., 2003) \\
\hline Finnish & 468 & $46,2 \ddagger$ & 0.028 & 20,2 & 0.466 & (Pasanen et al., 2006b) \\
\hline Chinese & 111 & $73,4 \%$ & 0.000 & $14,0 \%$ & 0.031 & (Xu et al., 2007) \\
\hline Pakistani & 180 & $50 \%$ & 0.005 & 23,9 & 0.826 & (Rajput et al., 2014) \\
\hline Malaysian & 100 & $87 \%$ & 0.000 & $11 \%$ & 0.003 & (Jada et al., 2007) \\
\hline Indian & 100 & $57 \%$ & 0.000 & $6,5 \%$ & 0.000 & (Jada et al., 2007) \\
\hline Tanzanian & 366 & $87 \%$ & 0.000 & $6 \%$ & 0.000 & (Aklillu et al., 2011) \\
\hline Macedonian & 266 & 40.9 & 0.364 & $13.7 \%$ & 0.008 & (Grapci et al., 2015) \\
\hline Albanian & 94 & 42 & 0.328 & $12.2 \%$ & 0.011 & (Grapci et al., 2015) \\
\hline Greek & 403 & 43 & 0.143 & $16 t$ & 0.041 & (Giannakopoulou et al., 2014) \\
\hline European & 151 & 41 & 0.375 & 18 & 0.224 & (Pasanen et al., 2008) \\
\hline Oceanian & 28 & $66 \%$ & 0.000 & $0 \%$ & 0.000 & (Pasanen et al., 2008) \\
\hline Ugandan & 115 & 78 & 0.000 & $3.9 \%$ & 0.000 & (Pasanen et al., 2008) \\
\hline Dutch & 74 & - & - & 18 & 0.331 & (Brunham et al., 2012) \\
\hline Israeli & 133 & 46 & 0.072 & 20 & 0.469 & (Pasanen et al., 2008) \\
\hline Korean & 24 & $75 \%$ & 0.000 & 25 & 0.847 & (Chung et al., 2005) \\
\hline Algerian & 29 & $64 \%$ & 0.000 & 17 & 0.458 & (Pasanen et al., 2008) \\
\hline Brazilian & 143 & $26 \%$ & 0.019 & $14 t$ & 0.020 & (Santos et al., 2012) \\
\hline Russian & 1071 & - & - & 22 & 0.770 & (Sychev et al., 2016) \\
\hline Sakha (Russian) & 76 & - & - & $11 \%$ & 0.007 & (Sychev et al., 2016) \\
\hline
\end{tabular}

${ }^{\mathrm{a}}$ The $\mathrm{p}$ value of the differences in allelic frequencies between Slovak and other population for c.388A $>\mathrm{G}$

${ }^{\mathrm{b}}$ The $\mathrm{p}$ value of the differences in allelic frequencies between Slovak and other population for c.521T $>\mathrm{C}$

$* 95 \% \mathrm{CI}$ : $95 \%$ Confidence interval 


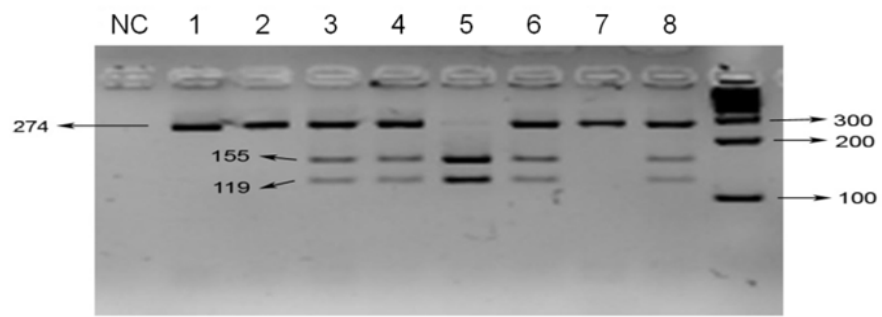

Fig. 1. PCR-RFLP analysis result for polymorphism 388A>G. Lane 1,2 and 7-wild type (AA), lane 3,4,6 and 8-heterozygotes (AG) lane 5 - homozygote for polymorphism $388 \mathrm{~A}>\mathrm{G}(\mathrm{GG})$

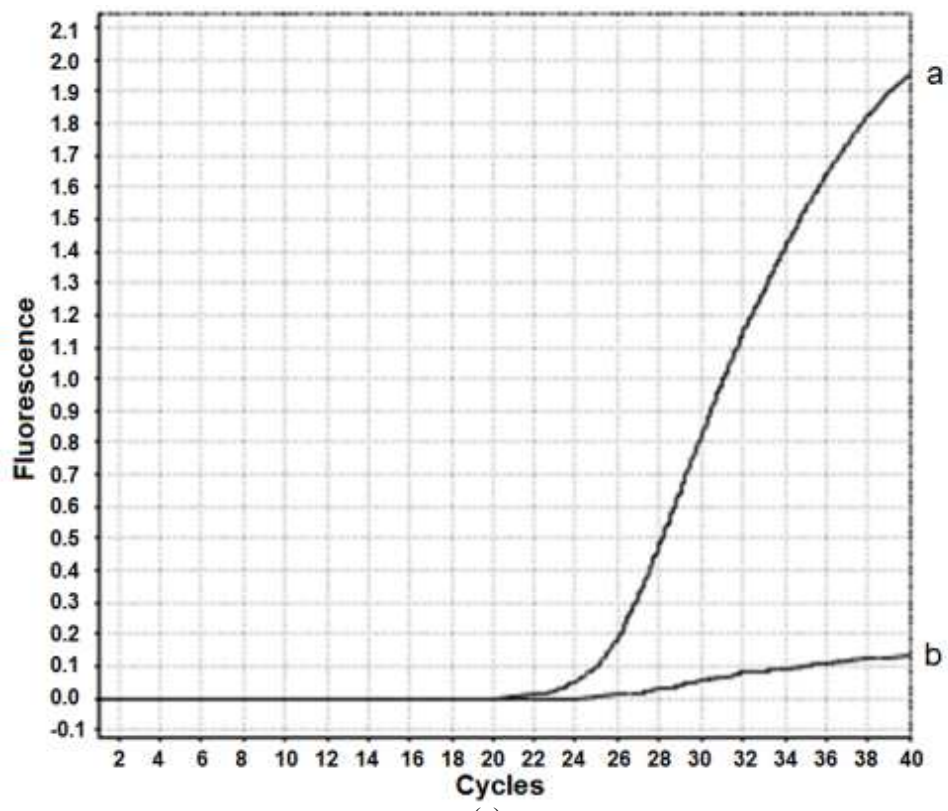

(a)

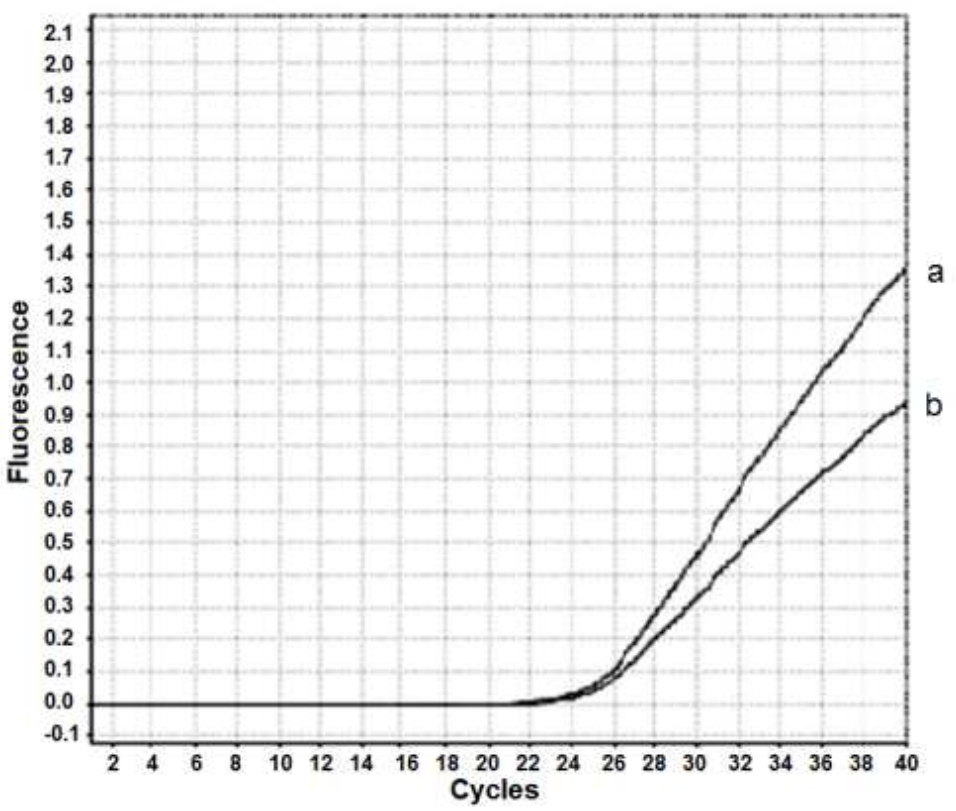

(b) 


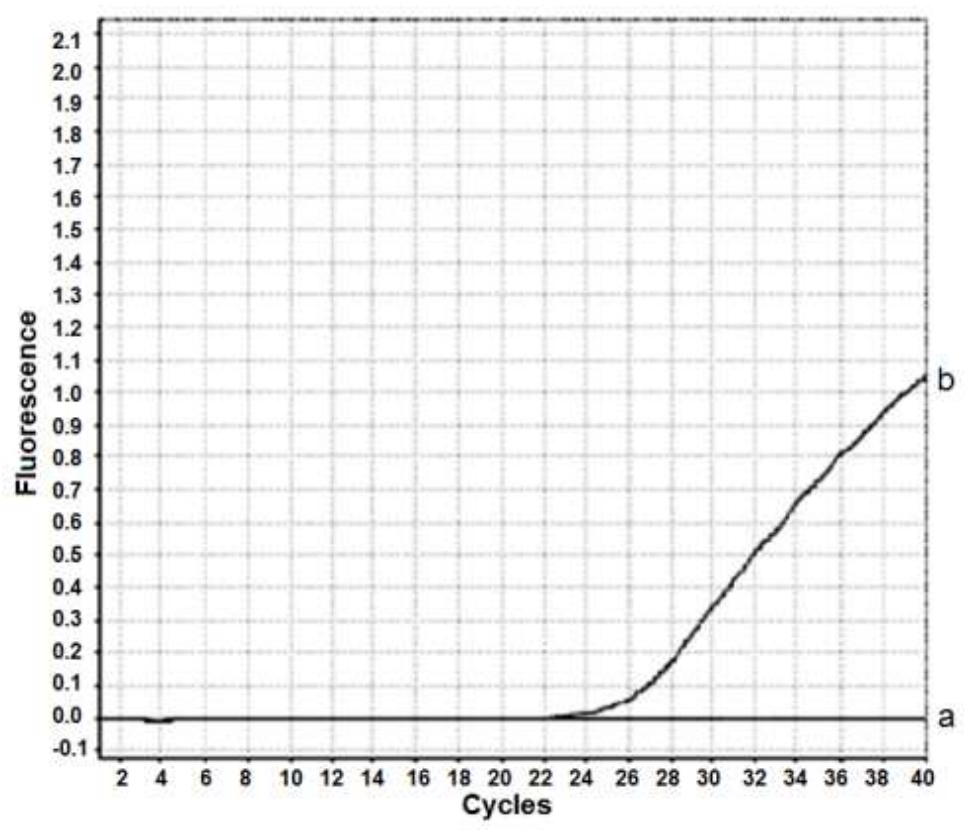

(c)

Fig. 2. Schematic pictures Allele-specific Real-Time PCR analysis for polymorphism c.521T $>$ C. 2a- wild type (TT), 2bheterozygote (TC), 2c- mutant (CC); a- wild type allele, b- mutant allele

Table 3. Genotype frequencies of SLCOIBI SNPs in subgroups of promoter region TATA box in UGT1A1 gene

\begin{tabular}{|c|c|c|c|c|c|c|c|}
\hline \multirow{2}{*}{$\begin{array}{l}\text { SNPs SLCOIBI } \\
\text { TATA genotype of UGT1A1 }\end{array}$} & \multicolumn{4}{|l|}{ c. $388 \mathrm{~A}>\mathrm{G}$} & \multicolumn{3}{|c|}{ c. $521 \mathrm{~T}>\mathrm{C}$} \\
\hline & $\mathrm{n}$ & AA $(\%)$ & AG $(\%)$ & GG (\%) & TT $(\%)$ & TC (\%) & $\mathrm{CC}(\%)$ \\
\hline (TA)6/(TA)6 & $29(35 \%)$ & 15 & 18 & 2 & 18 & 16 & 1 \\
\hline (TA)6/(TA)7 & $38(46 \%)$ & 18 & 21 & 7 & 30 & 11 & 4 \\
\hline (TA)7/(TA) 7 & $16(19 \%)$ & 7 & 8 & 4 & 10 & 10 & 0 \\
\hline
\end{tabular}

Correlation between studied SNP pairs was tested by pairwise linkage disequilibrium. The value was $\mathrm{r}^{2}=$ 0,18 and $\mathrm{D}^{\prime}=0,58$, this means that these polymorphisms are co-inherited for $58 \%$. The allelic frequencies at each locus were in Hardy-Weinberg equilibrium. In our study we found occurrence of all possible haplotypes for polymorphism c.388A $>\mathrm{G}$ and c. $521 \mathrm{~T}>\mathrm{C}$ with frequency for A-T $(S L C O 1 B 1 * 1 A)$ $57 \%$, A-C $(S L C O 1 B 1 * 5)$ 6,3\%, G-T $(S L C O 1 B 1 * 1 B)$ $19,6 \%$ and G-C $(S L C O 1 B 1 * 15) 17,1 \%$.

The frequency of causal mutation for Gilbert syndrome (TA7/TA7) was $19 \%$ in the studied cohort. Three subjects of this group (TA7/TA7) carried mutant genotype c.388GG in SLCO1B1 gene, which is $19 \%$ of individual with Gilbert syndrome (Table 3). These polymorphisms are not linked.

\section{Discussion}

Product of the gene $S L C O 1 B 1$ plays important role in the transport of numerous endogenous and exogenous compounds from blood into the liver cells.
Polymorphisms c.521T $>\mathrm{C}$ and c.388A $>\mathrm{G}$ decrease transport activity of the OATP1B1. These nonsynonymous substitutions have impact on the drug entry into the hepatocytes and increased drug plasma levels and therefore they modulate drugs therapeutic effects and enhance its toxicity. c.521T $>C$ polymorphism causes decreased clearance of pravastatin, simvastatin, ezetimibe glucuronide, SN-38 and bilirubin (Oswald et al., 2008; Zhang et al., 2007; Nozawa et al., 2005; Neuvonen et al., 2008). Polymorphisms in SLCO1B1 can be a further factor for hyperbilirubinemia and may be linked with Gilbert syndrome, as OATP1B1 is capable of transporting unconjugated bilirubin. However, the main factor for Gilbert syndrome is homozygous mutations in the promotor of bilirubin UDP-glucuronosyltransferase gene (Huang et al., 2004; 2005; Zhang et al., 2007). In the studied group with Gilbert syndrome, we found out $19 \%$ frequency of individuals carrying genotype c.388GG. In these subjects the risk of hyperbilirubinemia can be increased due to combined genetic factors. Because of low incidence of the genotype c.521CC we do not 
consider it to play part on unconjugated hyperbilirubinemia in the group of patients with Gilbert syndrome. Substantial health problem concerning this topic is relationship between SLCO1B1 SNPs and statininduced myopathy, which has been noted in many studies. Statins are generally considered as safe and welltolerated drugs, though, some users developed mild muscle impairment and in rare cases life-threatening rhabdomyolysis. Pasanen et al. (2006a) determined that homozygotes for $521 \mathrm{C}$ allele had higher plasma exposure to the active simvastatin acid than homozygotes for the wild $\mathrm{T}$ allele. However, recent study found no effect of c.521T $>C$ on the risk of statin-associated myopathy in dyslipidemic patients treated with low statin doses (Hubáček et al., 2015). The genotype c.388GG was associated with lower risk of myopathy (Link et al., 2008). In addition, c.388GG genotype causes significant increase in atorvastatin response (reduction of LDL cholesterol) and may be important marker for predicting efficiency of lipidlowering therapy (Rodrigues et al., 2011). Heterozygous carriers of $S L C O 1 B 1 * 15$ (388G, 521C) showed significantly higher plasma levels for pravastatin and pitavastatin compared to SLCO1B1 wild type carriers (Chung et al., 2005; Nishizato et al., 2003; Niemi et al., 2004). Discrepancy of data concerning the impact of statin therapy on myopathy is probably determined by the variety of therapeutic doses and/or type of statins. In 2012 guidelines for simvastatin treatment were suggested, in 2014 was this guideline updated and supplemented by short review about SLCO1B1 genotype and risk of myopathy for other statins. Lower dose of simvastatin or change type of statin in patient with $521 \mathrm{C}$ allele is recommended (Ramsey et al., 2014).

To the best of our knowledge, the current study is the first to show the frequencies of polymorphisms SLCO1B1 gene in Slovak population, which represents Western Slavic population. We analyzed SLCO1B1 SNPs in studied group to find out frequencies SLCO1B1 SNPs in Slovak population. We researched two common variants $521 \mathrm{~T}>\mathrm{C}(\mathrm{rs} 4149056)$ and $388 \mathrm{~A}>\mathrm{G}(\mathrm{rs} 2306283)$, which are in linkage disequilibrium (LD) and together form the four haplotypes $S L C O 1 B 1^{*} A(388 \mathrm{~A}, 521 \mathrm{~T})$, $S L C O 1 B 1 * 1 B(388 \mathrm{G}, 521 \mathrm{~T})$ SLCO1B1*5 (388A, 521C), $S L C O 1 B 1 * 15(388 \mathrm{G}, 521 \mathrm{C})$. The correlations of these SNP pairs were relatively low in Slovak population $r^{2}=$ 0,18 and $\mathrm{D}^{\prime}=0,58$.

We determined that the presence of minor allele c.388G was frequent (38\%) and frequency of mutant genotype was $13 \%$. On the other hand, the minor allele frequency of c.521C was almost half less (23\%) than $388 \mathrm{G}$ allele. When comparing our data with published studies, the most often occurring SNP c.388A $>\mathrm{G}$ in our studied population had a similar allelic frequency in
German (Mwinyi et al., 2008), Hungarian (Nagy et al., 2015), Macedonian, Albanian (Grapci et al., 2015) and Greek (Giannakopoulou et al., 2014) population. Frequency SNP c.388A $>$ G observed in African (78\%) (Mwinyi et al., 2008), Malaysian (87\%) (Jada et al., 2007), Tanzanian (87\%) (Aklillu et al., 2011), Korean (75\%) (Chung et al., 2005) and Chinese (73,4\%) (Xu et al., 2007) population was almost twice the frequency determined in our study. Higher incidence of SNP $388 \mathrm{~A}>\mathrm{G}$ was observed also in Japanese (64\%) (Nishizato et al., 2003), Indian (57\%) (Jada et al., 2007), Algerian (64\%), Oceanian (66\%) (Pasanen et al., 2008), Finnish (46,2\%) (Pasanen et al., 2006b), Pakistani (50\%) (Rajput et al., 2014) and Roma (Hungarian) (55\%) (Nagy et al., 2015) population. Compared to Slovak population, we determined significantly lower frequency only in Brazilian population (Santos et al., 2012). The incidence of SNP c.521T $>C$ in Slovak population $(23 \%)$ was slightly higher than in compared population of Caucasian and non-Caucasian origin, except for Russian (Sychev et al., 2016), where a similar frequency $(22 \%)$ was observed.

As we expected, the significantly different allele distribution for c.388A $>\mathrm{G}$ and c.521T $>\mathrm{C}$ was detected in African (Mwinyi et al., 2008), African American (Tirona et al., 2001), Chinese (Xu et al., 2007), Malaysian, Indian (Jada et al., 2007), Oceanian (Pasanen et al., 2008), Brazilian (Santos et al., 2012) and Tanzanian (Aklillu et al., 2011) population compared to Slovak population. These populations have different origin than Slovak population. We also found out difference in Macedonians, Albanians (Grapci et al., 2015), Greeks (Giannakopoulou et al., 2014) compare to Slovaks for c.521T $>$ C. Macedonians belong to South Slavic ethnic group, Albanian and Greek have their origin in the Middle East. It was interesting to find statistically significant difference between Slovak and Finnish (Pasanen et al., 2006b) population for c.388A $>\mathrm{G}$ and between Slovak and German (Mwinyi et al, 2008) for c.521T $>$ C, though all three ethnic populations belong to Caucasian population. The difference may be explained by higher genetic diversity of Europe population. Europe population is divided into several haplogroups. Slovak inhabitants have common ancestor with central and east Slavs. Finnish population belongs to Finno-Ugrian and origin of this population comes from Far East. Germans belong to Germanic ethnic group and they are genetically different than the Slavs.

We studied population variability between Slovak population and other countries. This study was done in sample of Caucasian origin, although Slovak population is not homogenous (substantial proportion of inhabitants are of Roma origin- for the future, it 
would be suitable to study also this group. Whereas in the case of Hungarian population difference with Roma population has been found).

Our result confirmed the different incidence of SLCO1B1 SNPs in different ethnic groups. This finding suggests, that the guideline for pharmacogenetic-testing should be designed with regards to population genetic structure.

\section{Conclusion}

Incidence of the most common SLCO1B1 SNPs is relatively common in Slovak population. Our study shows that frequency of c.388A $>\mathrm{G}$ and c.521T $>\mathrm{C}$ in Slovak population generally correlates with Caucasian population. It was interesting to find lower incidence than Finish population for c.388A $>\mathrm{G}$ and higher incidence than German population for c.521T $>\mathrm{C}$. SLCO1B1 genotyping may have clinical utility for adjusting doses of statin therapy to reduce the risk of myopathy development. By $S L C O 1 B 1$ genotyping it is necessary to take into account to ethnic differences in $S L C O 1 B 1$ SNPs. In Slovak population, the frequency of $S L C O 1 B 1$ SNPs is sufficient for consideration of molecular-genetic screening of SLCO1B1 SNPs in patients elected for treatment with drug involved in OATP1B1 mediated transport, mainly statin because of increased risk of myopathy.

\section{Acknowledgement}

We would like to thank RNDr. Ján Luha, CSc. for statistical analysis.

\section{Author's Contributions}

All author have read and given approval of the final manuscript version.

Mikulová Michaela: Administered the experiment and wrote the manuscript, designed the study, laboratory experiments and data analysis.

Kramarová Veronika: Has been involved in revising the manuscript critically for important intellectual content, has made substantial contributions to conception and design.

Chandoga Ján: Designed the experiment, interpreted results, has made substantial contributions to conception and design, and has been involved in drafting manuscript.

\section{Ethics}

This article contains unpublished results. The author declare no conflict of interest in this work.

\section{References}

Aklillu, E., S. Mugusi, E. Ngaimisi, M.M. Hoffmann and S. Konig et al., 2011. Frequency of the SLCO1B1 388A $>\mathrm{G}$ and the $521 \mathrm{~T}>\mathrm{C}$ polymorphism in Tanzania genotyped by a new LightCycler ${ }^{\circledR}$ based method. Eur. J. Clin. Pharmacol., 67: 1139-1145. DOI: 10.1007/s00228-011-1065-9

Boivin, A.A., H. Cardinal, A. Barama, V. Pichette and M.J. Hébert et al., 2010. Organic anion transporting polypeptide 1B1 (OATP1B1) and OATP1B3: Genetic variability and haplotype analysis in white Canadians. Drug. Metab. Pharmacokinet., 25: 508-155. PMID: 20877131

Brunham, L.R., P.J. Lansberg, L. Zhang, F. Miao and C. Carter et al., 2012. Differential effect of the rs4149056 variant in SLCO1B1 on myopathy associated with simvastatin and atorvastatin. Pharmacogenom. J., 12: 233-237. DOI: $10.1038 /$ tpj.2010.92

Carr, D.F., H. O'Meara, A.L. Jorgensen, J. Campbell and M. Hobbs et al., 2013. SLCO1B1 genetic variant associated with statin-induced myopathy: A proofof-concept study using the clinical practice research datalink. Clin. Pharmacol. Ther., 94: 695-701. DOI: $10.1038 /$ clpt.2013.161

Cvetkovic, M., B. Leake, M.F Fromm, G.R. Wilkinson and R.B. Kim, 1999. OATP and P-glycoprotein transporters mediate the cellular uptake and excretion of fexofenadine. Drug. Metab. Dispos., 27: 866-871. PMID: 10421612

Chung, J.Y., J.Y. Cho, K.S. Yu, J.R. Kim and D.S. Oh et al., 2005. Effect of OATP1B1 (SLCO1B1) variant alleles on the pharmacokinetics of pitavastatin in healthy volunteers. Clin. Pharmacol. Ther., 78: 342-350. DOI: 10.1016/j.clpt.2005.07.003

Donnelly, L.A., A.S. Doney, R. Tavendale, C.C. Lang and E.R. Pearson et al., 2011 Common nonsynonymous substitutions in SLCO1B1 predispose to statin intolerance in routinely treated individuals with type 2 diabetes: A go-DARTS study. Clin. Pharmacol. Ther., 89: 210-216. DOI: $10.1038 /$ clpt.2010.255

Gaunt, T.R., S. Rodríguez and I.N. Day, 2007. Cubic exact solutions for the estimation of pairwise haplotype frequencies: Implications for linkage disequilibrium analyses and a web tool 'CubeX'. BMC Bioinformat., 8: 428-428.

DOI: $10.1186 / 1471-2105-8-428$

Giannakopoulou, E., G. Ragia, V. Kolovou, A. Tavridou and A.D. Tselepis et al., 2014. No impact of SLCO1B1 521T $>\mathrm{C}, \quad 388 \mathrm{~A}>\mathrm{G}$ and $411 \mathrm{G}>\mathrm{A}$ polymorphisms on response to statin therapy in the Greek population. Mol. Biol. Rep., 41: 4631-4638. DOI: $10.1007 / \mathrm{s} 11033-014-3334-\mathrm{z}$ 
Grapci, A.D., A.J. Dimovski, A. Kapedanovska, M. Vavlukis and A Eftimov et al., 2015. Frequencies of single-nucleotide polymorphisms and haplotypes of the SLCO1B1 gene in selected populations of the western balkans. Balkan. J. Med. Genet., 18: 5-21. DOI: 10.1515/bjmg-2015-0001

Hagenbuch, B. and P.J. Meier, 2003. The superfamily of organic anion transporting polypeptides. Biochem. Biophys. Acta, 1609: 1-18. PMID: 12507753

Huang, C.S., M.J. Huang, M.S. Lin, S.S. Yang and H.C. Teng et al., 2005. Genetic factors related to unconjugated hyperbilirubinemia amongst adults. Pharmacogenet. Genom., 15: 43-50. PMID: 15864125

Huang, M.J., K.E. Kua, H.C. Teng, K.S. Tang and H.W. Weng et al., 2004. Risk factors for severe hyperbilirubinemia in neonates. Pediatr. Res., 56: 682-689.

DOI: 10.1203/01.PDR.0000141846.37253.AF

Hubáček, J.A., D. Dlouhá, V. Adámková, L. Zlatohlávek and O. Viklický et al., 2015. SLCO1B1 Polymorphism is not associated with risk of Statin-Induced Myalgia/Myopathy in a Czech Population. Med. Sci. Monit., 21: 1454-1459. DOI: org/10.12659/MSM.893007

Jada, S.R., S. Xiaochen, L.Y. Yan, X. Xiaoqiang and S. Lal et al., 2007. Pharmacogenetics of SLCO1B1: Haplotypes, htSNPs and hepatic expression in three distinct Asian populations. Eur. J. Clin. Pharmacol., 63: 555-563. DOI: 10.1007/s00228-007-0285-5

Link, E., S. Parish, J. Armitage, L. Bowman and S. Heath et al., 2008. SLCO1B1 variants and statininduced myopathy--a genomewide study. N. Engl. J. Med., 359: 789-99. DOI: 10.1056/NEJMoa0801936

Maeda, K., I. Ieiri, K. Yasuda, A. Fujino and H. Fujiwara et al., 2006. Effects of organic anion transporting polypeptide 1B1 haplotype on pharmacokinetics of pravastatin, valsartan and temocapril. Clin. Pharmacol. Ther., 79: 427-439. DOI: $10.1016 /$ j.clpt.2006.01.011

Mwinyi, J., K. Köpke, M. Schaefer, I. Roots and T. Gerloff, 2008. Comparison of SLCO1B1 sequence variability among German, Turkish and African populations. Eur. J. Clin. Pharmacol., 64: 257-266. DOI: $10.1007 / \mathrm{s} 00228-007-0409-y$

Nagy, A., C. Sipeky, R. Szalai, B.I. Melegh and P. Matyas et al., 2015. Marked differences in frequencies of statin therapy relevant SLCO1B1 variants and haplotypes between Roma and Hungarian populations. BMC Genet., 16: 108-108. DOI: org/10.1186/s12863-015-0262-4

Neuvonen, P.J., J.T. Backman and M. Niemi, 2008. Pharmacokinetic comparison of the potential over-thecounter statins simvastatin, lovastatin, fluvastatin and pravastatin. Clin. Pharmacokinet., 47: 463-474. DOI: $10.2165 / 00003088-200847070-00003$
Niemi, M., E. Schaeffeler, T. Lang, M.F. Fromm and M. Neuvonen et al., 2004. High plasma pravastatin concentrations are associated with single nucleotide polymorphisms and haplotypes of organic transporting polypeptide-C (OATP-C, SLCO1B1). Pharmacogenetics, 14: 429-440. PMID: 15226675

Nies, A.T., M. Niemi, O. Burk, S. Winter and U.M. Zanger et al., 2013. Genetics is a major determinant of expression of the human hepatic uptake transporter OATP1B1, but not of OATP1B3 and OATP2B1. Genome Med., 5: 1-1. DOI: 10.1186/gm405

Nishizato, Y., I. Ieiri, H. Suzuki, M. Kimura and K. Kawabata et al., 2003. Polymorphisms of OATP$\mathrm{C}$ (SLC21A6) and OAT3 (SLC22A8) genes: Consequences for pravastatin pharmacokinetics. Clin. Pharmacol. Ther., 73: 554-65.

DOI: 10.1016/S0009-9236(03)00060-2

Nozawa, T., H. Minami, S. Sugiura, A. Tsuji and I. Tamai, 2005. Role of organic anion transporter OATP1B1 (OATP-C) in hepatic uptake of irinotecan and its active metabolite, 7-ethyl-10hydroxycamptothecin: In vitro evidence and effect of single nucleotide polymorphisms. Drug. Metab. Dispos., 33: 434-9. DOI: 10.1124/dmd.104.001909

Oswald, S, J. König, D. Lutjohann, T. Giessmann and H.K. Kroemer et al., 2008. Disposition of ezetimibe is influenced by polymorphisms of the hepatic uptake carrier OATP1B1. Pharmacogenet Genom., 18: 559-68. DOI: 10.1097/FPC.0b013e3282fe9a2c

Pasanen, M.K., M. Neuvonen, P.J. Neuvonen and M. Niemi, 2006a. SLCO1B1 polymorphism markedly affects the pharmacokinetics of simvastatin acid. Pharmacogenet Genom., 16: 873-9. DOI: 10.1097/01.fpc.0000230416.82349.90

Pasanen, M.K., J.T. Backman, P.J. Neuvonen and M. Niemi, 2006b. Frequencies of single nucleotide polymorphisms and haplotypes of organic anion transporting polypeptide 1B1 SLCO1B1 gene in a Finnish population. Eur. J. Clin. Pharmacol., 62: 409-415. DOI: 10.1007/s00228-006-0123-1

Pasanen, M.K., P.J. Neuvonen and M. Niemi, 2008. Global analysis of genetic variation in SLCO1B1. Pharmacogenomics, 9: 19-33. DOI: $10.2217 / 14622416.9 .1 .19$

Rajput, T.A., A.K. Naveed, S. Khan and Z.U. Farooqi, 2014. Frequencies of two functionally significant SNPs and their haplotypes of organic anion transporting polypeptide1B1 SLCO1B1 gene in six ethnic groups of Pakistani population. Iran. J. Basic. Med. Sci., 17: 441-7. PMID: 25140206

Ramsey, L.B., S.G. Johnson, K.E. Caudle, C.E. Haidar and D. Voora et al., 2014. The clinical pharmacogenetics implementation consortium guideline for SLCO1B1 and simvastatin-induced myopathy: 2014 update. Clin. Pharmacol. Ther., 96: 423-428. DOI: $10.1038 /$ clpt.2014.125 
Rodrigues, A.C., P.M.S. Perin, S.G. Purim, V.N. Silbiger and F.D.V. Genvigir et al., 2011. Pharmacogenetics of OATP transporters reveals that $S L C O 1 B 1$ c. $388 \mathrm{~A}>\mathrm{G}$ variant is determinant of increased atorvastatin response. Int. J. Molecular Sci., 12: 5815-5827. DOI: 10.3390/ijms 12095815

Santos, P.C., A.C. Gagliardi, M.H. Miname, A.P. Chacra and R.D. Santos et al., 2012. SLCO1B1 haplotypes are not associated with atorvastatin-induced myalgia in Brazilian patients with familial hypercholesterolemia. Eur. J. Clin. Pharmacol., 68: 273-279. DOI: $10.1007 / \mathrm{s} 00228-011-1125-1$

Stewart, A., 2013. SLCO1B1 polymorphisms and statininduced myopathy. PLOS Curr. DOI: 10.1371/currents.eogt.d21e7f0c58463571bb0d9d3al 9b82203

Sychev, D.A., G.N. Shuev, J.V. Chertovskih, N.R. Maksimova and A.V. Grachev et al., 2016. The frequency of $S L C O 1 B 1 * 5$ polymorphism genotypes among Russian and Sakha (Yakutia) patients with hypercholesterolemia. Pharmgenomics Pers. Med., 9: 59-63. DOI: 10.2147/PGPM.S99634

Tirona, R.G., B.F. Leake, G. Merino and R.B. Kim, 2001. Polymorphisms in OATP-C: Identification of multiple allelic variants associated with altered transport activity among European- and AfricanAmericans. J. Biol. Chem., 276: 35669-35675. DOI: $10.1074 /$ jbc.M103792200

Treiber, A., R. Schneiter, S. Häusler and B. Stieger, 2007. Bosentan is a substrate of human OATP1B1 and OATP1B3: Inhibition of hepatic uptake as the common mechanism of its interactions with cyclosporin A, rifampicin and sildenafil. Drug. Metab. Dispos., 35: 1400-1407.

DOI: $10.1124 / \mathrm{dmd} .106 .013615$
Voora, D., S.H. Shah, I. Spasojevic, S. Ali and C.R. Reed et al., 2009. The SLCO1B1*5 genetic variant is associated with statin-induced side effects. J. Am. Coll. Cardiol., 54: 1609-1616. DOI: $10.1016 /$ j.jacc.2009.04.053

Wilke, R.A., L.B. Ramsey, S.G. Johnson, W.D. Maxwell and H.L. McLeod et al., 2012. The clinical pharmacogenomics implementation consortium: CPIC guideline for SLCO1B1 and simvastatininduced myopathy. Clin. Pharmacol. Ther., 92: 112-117. DOI: $10.1038 /$ clpt.2012.57

Xiang, X., Y. Han, M. Neuvonen, M.K. Pasanen and A. Kalliokoski et al., 2009. Effect of SLCO1B1 polymorphism on the plasma concentrations of bile acids and bile acid synthesis marker in humans. Pharmacogenet. Genom., 19: 447-57. DOI: 10.1097/FPC.0b013e32832bcf7b

$\mathrm{Xu}$, L.Y., Y.J. He, W. Zhang, S. Deng and Q. Li et al., 2007. Organic anion transporting polypeptide-1B1 haplotypes in Chinese patients. Acta Pharmacol. Sin., 28: 1693-7. DOI: 10.1111/j.1745-7254.2007.00643.x

Zhang, W., Y.J. He, Z. Gan, L. Fan and Q. Li et al., 2007. OATP1B1 polymorphism is a major determinant of serum bilirubin level but not associated with rifampicin-mediated bilirubin elevation. Clin. Exp. Pharmacol. Physiol., 34: 1240-1244. DOI: $10.1111 /$ j.1440-1681.2007.04798.x 